\title{
Inhaler choice and inhalation technique: key factors for asthma control
}

See linked review by Chrystyn and

Price on pg 243

*Federico Lavorinia, Mark L Levy', PN Richard Dekhuijzen', Graham K Crompton ${ }^{d}$ on behalf of the ADMIT Working Group

a Department of Internal Medicine, University of Florence, Italy

${ }^{b}$ Allergy and Respiratory Research Group, Centre of Population Health Sciences: GP Section, University of Edinburgh, Scotland, UK c Department of Pulmonary Diseases, University Medical Centre Nijmegen, Nijmegen, The Netherlands

'Western General Hospital, Edinburgh, UK

e Members of the Aerosol Drug

Management Improvement Team (ADMIT):

Peter J Barnes, London, UK; Mariëlle

Broeders, Nijmegen, The Netherlands;

Chris Corrigan, London, UK; Graham K

Crompton, Edinburgh, UK; Lorenzo

Corbetta, Firenze, Italy; Richard Dekhuijzen,

Nijmegen, The Netherlands; Jean

Christophe Dubus, Marseille, France;

Thomas Hausen, Essen, Germany; Meinhard Kneussl, Vienna, Austria; Federico Lavorini, Firenze, Italy; Mark L Levy, Edinburgh, UK; Søren Pedersen, Kolding, Denmark; Antonio Ramalho de Almeida, Porto, Portugal; Joaquin Sanchis, Barcelona, Spain; Jose L. Viejo, Hospital General Yagüe de Burgos, Spain; Walter Vincken, Brussels, Belgium; Thomas Voshaar, Moers, Germany

*Correspondence:

Dr Federico Lavorini,

University of Florence, Department of Internal Medicine, Section of

Immunoallergology, Respiratory Medicine and Cell Therapy, Viale GB. Morgagni 85, 50134, Florence, Italy

Tel: +39-055-413183

Fax: +39-055-4223202

E-mail: f.lavorini@dac.unifi.it

14th November 2009
Despite the availability of highly effective therapies and evidence-based guidelines, many patients with asthma continue to suffer symptoms and exacerbations, with considerable disruption to their daily life. ${ }^{1}$ This may reflect under-diagnosis and poor adherence to therapy, as well as incorrect use of inhalers. For good asthma control, it is essential to prescribe appropriate medication according to the severity of the patient's disease, and to ensure correct use of inhalers to facilitate effective drug delivery as well as adherence to the prescribed treatment. ${ }^{2}$

The drug treatment regimen for the vast majority of asthmatic patients is straightforward and is delivered as documented by national and international guidelines. The choice of drug delivery device is less clear. Asthma guidelines currently provide little practical guidance on selection of inhaler devices. Rather than being spoilt for choice, physicians are more frequently confused by the ever increasing number of drug/device combinations. ${ }^{3}$ Therefore, without a clear process to aid clinical decision-making, the choice of inhaler may be counterproductive and can result in very little improvement in asthma control.

Evidence from the literature demonstrates that when used correctly there is little difference in clinical efficacy between different device types. However, a large number of patients are unable to use their inhalers properly, with a consequent reduction in therapeutic benefit. ${ }^{5,6}$ It is evident that no single inhaler device can satisfy the needs of all; therefore it is important that the most suitable inhaler is chosen for each individual patient. The most effective inhaler for any given patient is the one that the patient can and will use effectively on a regular basis. Patient adherence to medical advice is an important factor because, even if a patient can use an inhaler, we cannot assume that it will be used as prescribed. Successful control of asthma relies heavily on patients' adherence to their prescribed inhaled therapies; it has been estimated that adherence rates for inhaler use are between $20 \%$ and $73 \%,{ }^{7}$ and a lack of adherence is associated with an increase in asthma-related adverse effects.

In this issue of the Primary Care Respiratory Journal, the excellent review by Chrystyn and Price $^{9}$ addresses problems associated with the use of pressurised metered-dose inhalers (pMDIs) and dry powder inhalers (DPIs), and summarises the use of each device by pointing out the positive and negative aspects of each. They also indicate factors to consider when prescribing an inhalation device, and, finally, describe the advantages of the newer hydrofluoroalkane-driven pMDIs which deliver ultrafine particles (unlike traditional pMDIs). However, little recognition has been given to the substantial role of nurses and pharmacists in either selecting appropriate inhaler devices for patients or in teaching and assessing inhaler technique. Trained asthma nurses fulfil a central role in education and in teaching patients about inhaler devices and encouraging adherence. ${ }^{10}$ Furthermore, communitybased pharmacists can play a huge role not only in demonstrating the correct use of each type of inhaler they dispense to a patient, but also in identifying poorly controlled asthma by scanning the use of, and dispensing patterns of, bronchodilators versus inhaled steroids." To facilitate educational programs the pharmaceutical industry should provide placebos for each type of inhaler it produces to every dispensing pharmacist and prescribing clinician, as well as to any member of the health care team, upon request, free of charge.

Chrystyn and Price ${ }^{9}$ stress the importance of regular patient education, but they do not address the need to update healthcare professionals' skills, knowledge and competence 
regularly. Many health professionals are limited in their ability to use inhaler devices properly ${ }^{12}$ and as a result they are not best placed to teach patients. There is a need to ensure that they are competent themselves to teach others.

Until now, there has been little clear comprehensive guidance to assist clinicians in the process of inhaler selection for their patients. General principles of inhaler selection and use have been reviewed in detail with a list of eight points to consider. ${ }^{4}$ An algorithm incorporating the patient's inspiratory flow and ability to coordinate pMDI actuation with inspiration has been also proposed. ${ }^{13}$ More recently, the Aerosol Drug Management Improvement Team (ADMIT), a consortium of European respiratory physicians with a common interest in promoting excellent delivery of inhaled drugs, proposed a practical algorithm to facilitate patients' instruction on optimal inhaler use. ${ }^{14}$ At each consultation, the physician should establish the patient's current level of asthma control: if the disease has been well controlled for $\geq 3$ months, therapy should be stepped down gradually according to guidelines; conversely, if the patient is poorly controlled, adherence to medical advice and (most importantly) inhalation technique should be assessed. If the patient is unable to use a particular inhaler correctly despite repeated attempts after instruction, an alternative inhaler should be considered. In cases where ongoing uncontrolled asthma persists despite correct inhaler technique, asthma therapy should be stepped up according to guidelines. Although there is no evidence that patients' compliance is improved by changing to a different inhaler, it is likely that this strategy will be cost effective since it could facilitate control of asthma without increasing drug dosage or adding other agents.

We now need effectiveness studies, especially in the real world, to see whether this approach is applicable to the treatment of asthma patients in the community. We believe that choosing a method of drug administration in patients with obstructive airways diseases is as critical as the choice of medication itself, and that in future the choice of a new compound will be secondary to the need to choose the appropriate inhaler device.

\section{The ADMIT Working Group}

ADMIT is a consortium of European respiratory clinicians with special expertise in inhalation therapy who review published evidence to examine ways of improving the treatment of obstructive pulmonary airway diseases in Europe. ADMIT is supported by an unrestricted educational grant from MEDA AB. Members of ADMIT receive a small honorarium from MEDA $A B$ for attending meetings, and travel expenses are reimbursed. See the first ADMIT paper published in this journal ${ }^{14}$ for a full list of individual conflict of interest declarations.

\section{Conflict of interest declaration}

Mark L Levy is the Editor-in-Chief of the PCRJ, but was not involved in the editorial review of, nor the decision to publish, this article.

\section{References}

1. Rabe KF, Vermeire PA, Soriano JB, Maier WC. Clinical management of asthma in 1999: the Asthma Insights and Reality in Europe (AIRE) study. Eur Respir J 2000; 16:802-07.

2. Haynes RB, McDonald H, Garg AX, Montague P. Interventions for helping patients to follow prescriptions for medications. Cochrane Database Syst Rev 2002; 2: CD000011.

3. Crompton GK. How to achieve good compliance with inhaled asthma therapy. Respir Med 2004;98:s35-s40. http://dx.doi.org/10.1016/j.rmed.2004.07.014

4. Dolovich MB, Ahrens RC, Hess DR, et al. Device selection and outcomes of aerosol therapy: evidence-based guidelines: American College of Chest Physicians/American College of Asthma, Allergy, and Immunology. Chest 2005; 127:335-71. http://dx.doi.org/10.1378/chest.127.1.335

5. Crompton GK. Barnes PJ, Broeders $M$, et al. The need to improve inhalation technique in Europe: A report from the Aerosol Drug Management Improvement Team. Respir Med 2006;100:1479-94. http://dx.doi.org/ 10.1016/j.rmed.2006.01.008

6. Lavorini F, Magnan A, Dubus JC, et al. Effect of incorrect use of dry powder inhalers on management of patients with asthma and COPD. Respir Med 2008; 102:593-604. http://dx.doi.org/10.1016/j.rmed.2007.11.003

7. Cochrane M, Bala M, Downs K, Mauskopf J, Ben Joseph R. Inhaled corticosteroids for asthma therapy: patient compliance, devices, and inhalation technique. Chest 2000;117:542-50. http://dx.doi.org/10.1378/ chest.117.2.542

8. Jones C, Santanello N, Boccuzzi S, Wogen J, Strub P, Nelsen L. Adherence to prescribed treatment for asthma: evidence from pharmacy benefits data. $J$ Asthma 2003:40:93-101.

9. Chrystyn $H$, Price D. Not all asthma inhalers are the same: factors to consider when prescribing an inhaler. Prim Care Resp J 2009;18(4):243-9 http://dx.doi.org/10.4104/pcrj.2009.00029

10. Upton J, Madoc-Sutton H, Sheikh A, Frank T, Walker S, Fletcher M. National survey on the roles and training of primary care respiratory nurses in the UK in 2006: are we making progress? Prim Care Resp J 2007;16:284-90. http://dx.doi.org/10.3132/pcrj.2007.00068

11. Basheti IA, Armour CL, Bosnic-Anticevich, SZ, Reddel HK Evaluation of a novel educational strategy, including inhaler-based reminder labels, to improve asthma inhaler technique. Patient Education and Counseling 2008;72:26-33. http://dx.doi.org/10.1016/j.pec.2008.01.014

12. Hanania NA, Wittman R, Kesten S, Chapman KR. Medical personnel's knowledge of and ability to use inhaling devices. Metered-dose inhalers, spacing chambers, and breath-actuated dry powder inhalers. Chest 1994;105: 111-16.

13. Chapman KR, Voshaar TH, Virchow JC. Inhaler choice in primary practice. European Respiratory Review 2005;14(96):117-22. http://dx.doi.org/10.1183/ 09059180.05.00009607

14. Dekhuijzen PNR, Magnan A, Kneussl M, on behalf of the ADMIT Working Group. The ADMIT series - Issues in Inhalation Therapy. 1) The goals of asthma treatment: can they be achieved? Prim Care Resp J 2007;16:341-8. http://dx.doi.org/10.3132/pcrj.2007.00081

Available online at http://www.thepcrj.org 